\title{
COVID-19, UNA PANDEMIA DE PELÍCULA: ANÁLISIS DE PROBLEMAS ÉTICOS
}

\section{COVID-19, a Movie Pandemic: Analysis of Ethical Problems}

\author{
Celia VICENTE MARTÍNEZª; Carmen ÁLVAREZ GALÁN ; Isolina RIAÑO-GALÁNª,c \\ ${ }^{a} A G C$ de Pediatría. Hospital Universitario Central de Asturias, Oviedo. ${ }^{\text {E} E s t u d i a n t e ~ d e l ~ G r a d o ~ e n ~ M e d i c i n a . ~}$ \\ Universidad de Oviedo. 'IUOPA-Departamento de Medicina-ISPA, Universidad de Oviedo. CIBER de Epidemiología y \\ Salud Pública (CIBERESP) (España). \\ Correo electrónico: rianoisolina@uniovi.es
}

Fecha de recepción: 15 de septiembre de 2020

Fecha de aceptación: 22 de septiembre de 2020

Fecha de publicación: 29 de enero de 2021

\section{Resumen}

El panorama mundial resultante de la pandemia vivida por el nuevo SARS-CoV-2 y la enfermedad que produce, la COVID-19 ha puesto de manifiesto nuestra fragilidad no solo como individuos sino como sociedad. La gestión de recursos escasos, la transparencia de la información, los riesgos asumidos por los sanitarios, el acompañamiento al final de la vida o la búsqueda de una vacuna segura son solo algunos de los desafíos éticos que han aflorado durante la crisis sanitaria. Previamente, el cine y la literatura ya habían mostrado estos aspectos éticos en situaciones extremas como la actual, basándose en pandemias históricas y otras de ciencia ficción que describen un mundo distópico. La reflexión colectiva y la prudencia deben ser el epicentro que muevan a tomar decisiones solidarias en el ámbito social, científico y político para alejarnos de un futuro desalentador, en el nuevo mundo tras la COVID-19.

Palabras clave: Pandemia; ética; priorización; profesionalidad; investigación; vacunas.

\section{Abstract}

The global panorama resulting from the pandemic experienced by the new SARS-CoV-2 and the disease it produces, COVID-19 has highlighted our fragility not only as individuals but as a 


\section{COVID-19, UNA PANDEMIA DE PELÍCULA: ANÁLISIS DE PROBLEMAS ÉTICOS \\ CELIA VICENTE MARTÍNEZ; CARMEN ÁLVAREZ GALÁN; ISOLINA RIAÑO-GALÁN}

society. Management of scarce resources, transparency of information, risks assumed by the health workers, support at the end of life or the search for a safe vaccine are just some of the ethical challenges that have emerged during the health crisis. Previously, cinema and literature had already shown these ethical aspects in extreme situations such as the current one, based on historical pandemics and other science fiction that describe a dystopian world. Collective reflection and prudence must be the epicenter that move us to make solidarity decisions in the social, scientific and political spheres to move away from a discouraging future, in the new world after COVID-19.

Keywords: Pandemic; ethics; priorization; professionalism; investigation; vaccine.

INTRODUCCIÓN: YA NOS LO HABÍAN CONTADO

"Todo lo que puede ganar al juego de la peste y de la vida es el conocimiento y el recuerdo" (Albert Camus. La Peste ${ }^{1}$ )

Albert Camus, ya a mediados del siglo XX, a través de su novela La Peste dignifica como armas la memoria y el conocimiento de las epidemias pasadas para anteponerse a las venideras.

Desde las diez plagas de Egipto, relatadas en el antiguo Testamento, somos conocedores de las sucesivas epidemias que han asolado a la humanidad. La peste de Justiniano en el Imperio Bizantino, la peste negra en Europa, la viruela en el nuevo mundo, la gripe española que combatió al lado de las tropas de la Gran Guerra, y más recientemente la gripe aviar o el SIDA son solo algunos ejemplos, la punta de un témpano de hielo que puede tener consecuencias devastadoras, pero no tan impredecibles como creíamos. Epidemias que, tal y como expone Diego Gracia, son fenómenos históricos, culturales, que emergen en relación con la actividad humana y alteran el equilibrio ecológico del medio en que vivimos ${ }^{2}$.

El cine y la literatura han sido uno de los vehículos de difusión de las pandemias sucedidas a lo largo de la historia, así como otras que simulaban un escenario de ciencia ficción, haciendo ahora cuestionarnos si no habían sido clarividentes de la situación que desde hace unos meses ha descompuesto la arquitectura global del mundo en que vivimos.
Ya habíamos sido espectadores de escenarios literarios y cinematográficos que teatralizaban las distintas perspectivas desde las que se puede abordar una catástrofe mundial, de los problemas que genera y de las emociones que suscita en una población que, a pesar del conocimiento, no estaba preparada para un golpe de tal envergadura.

Algunas de las epidemias previas, quizá por su forma de transmisión como el SIDA, el ébola o el cólera, afectaban más a ciertos territorios o determinadas poblaciones y por lo tanto para los robustos estados europeos del bienestar creados a raíz de la segunda guerra mundial eran quiméricas, lejanas o simplemente creían estar en un camino hacia la vejez por el que iban a pasear sin tambalearse. La COVID-19, en cambio, nos ha sorprendido a todos. Desde el niño que juega al fútbol en una aldea de Senegal, hasta el acaudalado millonario del primer mundo.

Pero ¿tiene algún papel la ética en estas situaciones de catástrofe? La ética es tanto más necesaria cuanto más difíciles son las circunstancias que afrontamos, cuantos más valores están amenazados. La ética nos enseña a descubrir los valores que están detrás de los hechos. En estos meses, sociedades científicas y organizaciones bioéticas de forma proactiva, han promovido reflexiones éticas que han intentado orientar las decisiones y fortalecer el sentido de la tarea de nuestros sanitarios ${ }^{3,4}$.

Se han publicado multitud de artículos, que plantean cuestiones fundamentales: ¿Qué debemos hacer?, ¿qué es lo correcto?, ¿̇qué sabemos 


\section{COVID-19, UNA PANDEMIA DE PELÍCULA: ANÁLISIS DE PROBLEMAS ÉTICOS \\ CELIA VICENTE MARTÍNEZ; CARMEN ÁLVAREZ GALÁN; ISOLINA RIAÑO-GALÁN}

y qué es cierto?, ¿tiene sentido el aislamiento de las sociedades?, ¿debemos permitir la muerte en soledad?, ¿cómo buscar el equilibrio entre vigilancia y respeto a la privacidad?

En este artículo pretendemos reflexionar sobre algunos de los problemas éticos vividos en la actualidad, conscientes de la limitación que supone analizar una situación en la que aún estamos inmersos, y verlos reflejados en escenas de "ciencia ficción".

Han sido de interés para este proyecto películas como Contagio (Contagion, 2011; Steven Soderbergh), 93 días (93 days, 2016; Steve Gukas), Virus (Gamgi, 2013; Kim Sung Soo), EstaIlido (Outbreak, 1995; Wolfgang Petersen), 12 monos (12 monkeys, 1995; Terry Gilliam), Soy leyenda (I am legend, 2007; Francis Lawrence) recogidas en la tabla 1 . Así como novelas como $L a$ Peste (1947) de Albert Camus ${ }^{1}$ o Némesis (2010) de Philip Roth ${ }^{5}$.

\section{LA ÉTICA, ¿SUPERFLUA O PROTAGONISTA EN UNA PANDEMIA?}

Los cuatro principios clásicos de la bioética (autonomía, beneficencia, justicia y no maleficencia) pueden ser considerados valores básicos que constituyen el marco para tomar decisiones correctas y buenas. En el ámbito de la ética clínica se otorga la prioridad a cada persona. Los profesionales sanitarios sienten la responsabilidad de cuidarlas, buscan hacer el bien (beneficencia), respetando sus valores y preferencias (autonomía).

Tabla 1. Listado de películas de cine con epidemias como argumento principal.

\begin{tabular}{|c|c|c|c|}
\hline Título & Año & Director & Resumen \\
\hline Estallido (Outbreak) & 1995 & Wolfgang Petersen & $\begin{array}{l}\text { El ejército de EEUU intenta erradicar un poblado con un } \\
\text { virus mortal; todo se complica cuando un mono portador } \\
\text { viaja desde la República del Zaire a América y contagia a } \\
\text { la población. }\end{array}$ \\
\hline $\begin{array}{l}12 \text { monos } \\
\text { (12 monkeys) }\end{array}$ & 1995 & Terry Gilliam & $\begin{array}{l}\text { En el año 2035, los supervivientes de una pandemia se } \\
\text { refugian en comunidades subterráneas, húmedas y frías. } \\
\text { Un criminal convicto es enviado al pasado para conseguir } \\
\text { una muestra del virus con el objetivo de elaborar un } \\
\text { antídoto. }\end{array}$ \\
\hline $\begin{array}{l}\text { Soy leyenda } \\
\text { (I am legend) }\end{array}$ & 2007 & Francis Lawrence & $\begin{array}{l}\text { La expansión de un virus convierte a los seres humanos en } \\
\text { vampiros mutantes. Un único hombre es el superviviente } \\
\text { y busca en su sangre inmune la vuelta de la humanidad. }\end{array}$ \\
\hline Contagio (Contagion) & 2011 & Steven Soderbergh & $\begin{array}{l}\text { Una norteamericana en un viaje de negocios a Hong Kong } \\
\text { contrae un virus que se contagia rápidamente generando } \\
\text { una epidemia global con millones de muertes. }\end{array}$ \\
\hline $\begin{array}{l}\text { Virus } \\
\text { (Gamgi) }\end{array}$ & 2013 & Kim Sung Soo & $\begin{array}{l}\text { Al abrir un contenedor donde se transportan inmigrantes } \\
\text { ilegales, se propaga una mutación del virus de la gripe } \\
\text { aviar. Uno de ellos consigue sobrevivir siendo la única } \\
\text { cura. }\end{array}$ \\
\hline $\begin{array}{l}93 \text { días } \\
\text { (93 days) }\end{array}$ & 2016 & Steve Gukas & $\begin{array}{l}\text { Cuando un hombre con síntomas de ébola llega a una } \\
\text { megaciudad de más de } 21 \text { millones de personas, un } \\
\text { grupo de médicos intentará contener la propagación de la } \\
\text { enfermedad. }\end{array}$ \\
\hline
\end{tabular}




\section{COVID-19, UNA PANDEMIA DE PELÍCULA: ANÁLISIS DE PROBLEMAS ÉTICOS \\ CELIA VICENTE MARTÍNEZ; CARMEN ÁLVAREZ GALÁN; ISOLINA RIAÑO-GALÁN}

En la actual emergencia sanitaria el foco ya no está en el individuo sino en la comunidad. Aunque los principios de la bioética se aplican en el ámbito de la salud pública, se prioriza la salud de la comunidad asumiendo la responsabilidad de promover la igualdad de las personas y la equidad en la distribución de riesgos y beneficios (justicia). Otros principios importantes son la solidaridad y la búsqueda del bien común, que pueden justificar una limitación de los derechos y preferencias de los individuos. Para conseguir que ambos ámbitos guarden equilibrio, sin confundirse, se ha propuesto el siguiente marco ético general: 1ㅇ) el deber de planificar gestionando la incertidumbre, 20) el deber de salvaguardar apoyando a los trabajadores y protegiendo a las poblaciones vulnerables, y 3 ㅇ) el deber de guiar indicando los niveles de atención de contingencia y los estándares de atención en caso de crisis ${ }^{6}$. En el horizonte deben seguir estando presentes los fines de la medicina ${ }^{7}$ : la prevención de enfermedades y promoción de la salud; aliviar el sufrimiento causado por la enfermedad; curar y cuidar; evitar la muerte antes de tiempo y acompañar a una muerte tranquila.

En situaciones de emergencia las soluciones a los problemas tienden a ser extremas, pudiendo existir un conflicto entre dos deberes: 1) el deber de cuidado que nos obliga a no abandonar al paciente, aliviar el sufrimiento, y respetar los derechos y preferencias de los pacientes y 2) el deber de justicia que nos obliga a la distribución equitativa de los recursos y a ponderar las decisiones teniendo en cuenta el bien común y no sólo el bien individual. Se trata de la justicia distributiva, referida a la distribución equitativa de derechos, beneficios y cargas sociales, sabiendo que los bienes son escasos y las necesidades múltiples.

La tabla 2 recoge los principales problemas éticos que hemos identificado, algunos de los cuales vamos a analizar.

\section{GESTIÓN DE RECURSOS ESCASOS Y CRITERIOS DE PRIORIZACIÓN}

La palabra crisis proviene del griego Krisis que significa separar o decidir. La bioética puede ayudarnos a tomar buenas decisiones con intervenciones científicas y clínicas adecuadas frente al virus y medidas personales, sociales y económicas.

En la película Virus (Gamgi, 2013, Kim Sung Soo) cuando una epidemia se expande la sociedad entra en pánico, colapsando la ciudad y el sistema sanitario. Se intenta aislar a todos los

Tabla 2. Problemas éticos identificados en la pandemia COVID-19

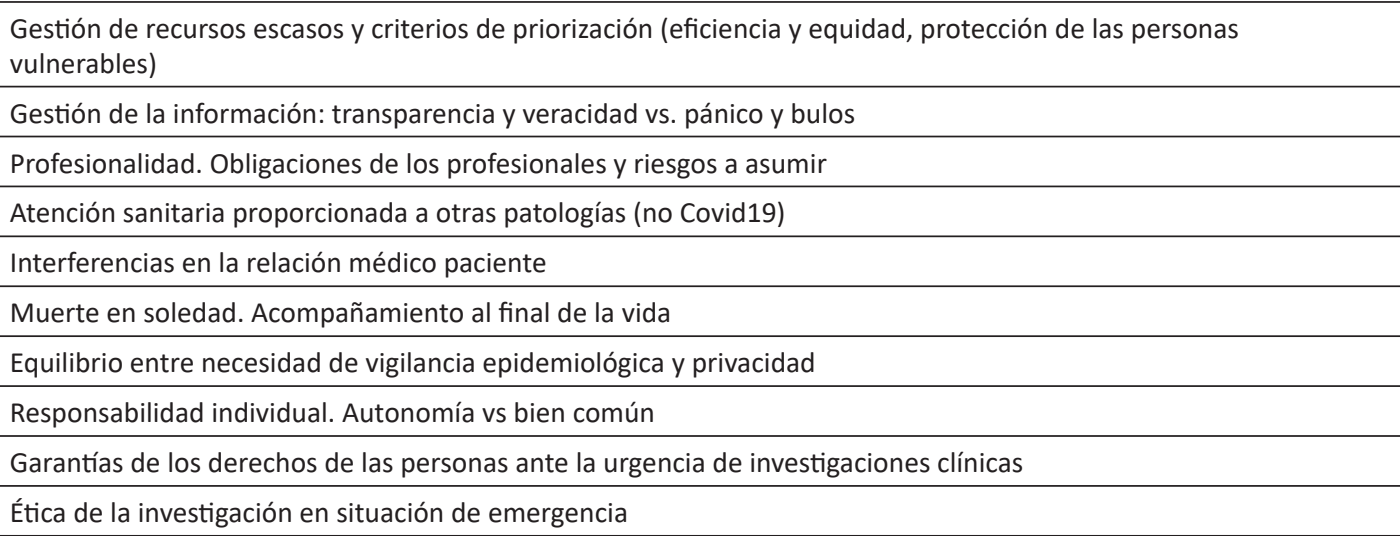


contagiados ante la falta de personal médico y la escasez de ambulancias. Una vez se establece la cuarentena, la población se traslada a un campamento dónde la inquietud aumenta por el apagón de comunicaciones y las condiciones de vida difíciles. En algunas escenas, se observa como los infectados se abandonan en un aparcamiento en el suelo sin camas, mantas, ni personal sanitario que los cuide.

En la realidad, la evolución exponencial de la pandemia colapsó la capacidad de los servicios sanitarios y en especial de cuidados intensivos. De forma temporal, pero intensa, un desequilibrio entre las necesidades clínicas y la disponibilidad efectiva de los recursos sanitarios hizo que se manejara la situación en base a una medicina de catástrofe.

Hay dos maneras de distribuir recursos ${ }^{8}$. El enfoque utilitarista prioriza el criterio de eficiencia: los recursos deben utilizarse en aquellas personas que más puedan beneficiarse de ellos. El segundo enfoque, basado en Rawls, considera que los recursos deben distribuirse de acuerdo con el criterio de equidad de forma que lleguen a todos por igual, o que, en caso de desigualdad, tengan preferencia aquellos que más los necesitan, es decir, los más frágiles, los más desprotegidos.

Ambos enfoques son complementarios. El criterio de equidad obliga a que los beneficios y cargas se distribuyan por igual. El principio de eficiencia ayuda a decidir qué grupos se beneficiarán más de la utilización de los recursos. Nuestra sociedad considera que la opción más correcta es la que conjuga ambos criterios, eficiencia y equidad, buscando una postura intermedia que incorpore las garantías de universalización, transparencia y obligación de no abandono. Se debe cuidar e implementar atención proporcionada al grupo más vulnerable al que no se puedan aplicar todas las medidas. Las medidas de limitación deben activarse de forma escalonada adaptándose a los escenarios de la crisis.
Hubo que decidir quién puede beneficiarse más de un respirador mediante un sistema de triaje al que no estábamos acostumbrados, pues los países del primer mundo nunca se habían visto envueltos en una situación de escasez no solo de alta tecnología como los respiradores sino de material básico como mascarillas y batas sustituidas, en algunos casos, por bolsas de plástico.

La emergencia sanitaria ha puesto contra las cuerdas los principios éticos, pues resulta difícil estar preparado para tomar decisiones, muchas veces de urgencia, en las que haya que priorizar el bien común cuando alguien pierde la vida ante tus ojos ${ }^{9}$. Por ese motivo es recomendable que sea distinto el equipo de triaje de aquellos encargados de la atención clínica. Conviene recordar un recurso disponible para asesoramiento como son los Comités de Ética Asistencial.

Quizás hayamos vuelto a un paternalismo en el que los profesionales deciden qué vida merece inversión de más recursos, sin posibilitar otras consideraciones más allá de las biológicas ${ }^{10}$. Quizás se haya obviado por diversas circunstancias, hablar con el enfermo, conocer sus valores y sus expectativas, haciéndole partícipe en la toma de decisiones en la medida de lo posible.

Tal y como recoge el Posicionamiento de la Sociedad Española de Medicina Geriátrica no es tolerable una situación de discriminación en la atención sanitaria recibida en función de la edad cronológica ${ }^{11}$. La situación funcional y de fragilidad deberán ser los criterios prioritarios en la toma de decisiones y en las estrategias de asignación de ingreso en $\mathrm{UCl}$. Se ha puesto el foco en situaciones extremas (pongo o no pongo el respirador, ingreso o no ingreso en $\mathrm{UCl}$ ) olvidando que hay otras opciones intermedias a las que se llega mediante la deliberación, el método de la ética, que requiere reflexión colectiva y prudencia. 


\section{COVID-19, UNA PANDEMIA DE PELÍCULA: ANÁLISIS DE PROBLEMAS ÉTICOS \\ CELIA VICENTE MARTÍNEZ; CARMEN ÁLVAREZ GALÁN; ISOLINA RIAÑO-GALÁN}

INFORMACIÓN DE LA SOCIEDAD: TRANSPARENCIA Y VERACIDAD VS. PÁNICO Y BULOS.

Cuando revisamos la historia del cine, parece que el ser humano se convierte en un ser predecible y por lo tanto vulnerable, puesto que este pánico ante la desinformación y el desconocimiento ya se ponían de manifiesto en películas como Estallido (Outbreak, 1995, Wolfgang Petersen), donde en el estudio de una epidemia causada por el virus "motaba" en Zaire, con un índice de mortalidad del $100 \%$, se descubre que treinta años antes los militares ya habían tenido el virus y no se utilizó su plasma como tratamiento para encubrir una posible arma biológica, o Contagio (Contagion, 2011, Steven Soderbergh) en la que un periodista engaña a las masas promocionando un medicamento como la cura de una nueva enfermedad que se ha convertido en una epidemia global.

En diciembre de 2019 se notificaban casos de neumonía bilateral con evolución tórpida en Wuhan, China, debidos a un nuevo coronavirus. En poco tiempo los medios de comunicación lo daban a conocer al resto del mundo. Sin embargo, parece que la provincia de Hubei era desconocida para muchos o estaba muy lejos para otros; tanto como para categorizar a este nuevo virus de ficticio y sumergirse en una primera fase de negación, como si de las fases del duelo de Kubler Ross se tratase ${ }^{12}$. A la negación por el desconocimiento ha seguido el pánico por la incertidumbre de una sociedad desconcertada ante las discrepancias de la información transmitida por los medios mediante un lenguaje emotivo, para infundir ánimos; científico, para hablar de estadísticas y estudios de investigación; político, para debatir las medidas adoptadas y, sobre todo, un lenguaje bélico que nos ha sumergido en "la guerra contra el coronavirus". Este último ha sido el predominante. Aun aceptando su sentido metafórico, este lenguaje origina dos errores. El primero es un error de diagnóstico pues se debe hablar de crisis de salud pública, no tanto de una guerra. El segundo es un error de enfoque y tratamiento, pues el estado de guerra alumbra un modelo de relación que implica una toma de decisiones excepcionales, más allá del juicio moral y de las normas comunes ${ }^{13}$.

A diario se solapaban multitud de noticias en televisión, prensa, redes sociales... Unas fundadas en argumentos científicos, que no alcanzaban la evidencia suficiente, y otras que han dado paso a los bulos o fake news. La necesidad o no de usar mascarilla, la forma de contagio, quién es más vulnerable, los niños como portadores asintomáticos y casi estigmatizados como arma biológica.

La comunicación acerca de la mayor afectación y gravedad en las personas ancianas o la situación vivida en algunas residencias de mayores ha generado una inquietud adicional. No debemos olvidar la obligación de respeto y cuidado que como sociedad tenemos hacia las personas ancianas y más vulnerables y eso debe reflejarse en los mensajes que se difunden.

El desconocimiento conduce al temor y el temor al pánico. La necesidad de buscar respuestas crea un repertorio de falsas esperanzas. Promovamos una información fiable y de calidad que garantice un adecuado conocimiento de nuestra historia pasada, presente y futura.

\section{OBLIGACIONES DE LOS PROFESIONALES Y RIESGOS A ASUMIR}

"Debemos hacer nuestro trabajo como
hacemos cada día con cada paciente que
entre por nuestra puerta. Nos formamos
para esto. Podemos hacerlo. Podemos
y debemos. Todos somos profesionales,
actuamos como profesionales" (93 días,
2016)

La película 93 días (93 days, 2016; Steve Gukas) basada en hechos reales, es la representación del heroísmo, abnegación y sacrificio de los profesionales sanitarios. En 2014, un grupo de trabajadores luchan por contener un brote de ébola en la ciudad de Lagos (Nigeria), con más de 
21 millones de habitantes. Durante 93 días una enfermedad con una tasa de fallecimiento del $99 \%$ solo se cobra 9 víctimas, la mayoría sanitarios.

Las facultades de medicina y enfermería tienen la responsabilidad de formar profesionales que sean capaces de ver no solo cuerpos con patologías o datos, sino personas concretas con una biografía en situación de fragilidad.

Se debe promover la empatía y la compasión entendida como el reconocimiento del sufrimiento que mueve a procurar aliviarlo, actuar en favor de la salud y la vida, actualizar los conocimientos y habilidades. Asumir que la responsabilidad y el cuidado son los ejes de la profesión. Esas son las obligaciones de un profesional sanitario, que por otra parte no deja de ser humano y por lo tanto, también, vulnerable. Es humano que reconozcan sus síntomas de agotamiento y pidan ayuda. Profesionales sanitarios que insisten en que no son héroes. El héroe debe aceptar riesgos desproporcionados sin apoyo social adecuado o responsabilidad compartida.

Se ha puesto a prueba su resiliencia. Han caminado al borde del abismo manejando esta nueva enfermedad desde el desconocimiento, a veces desprovistos de los equipos de protección apropiados, asumiendo el riesgo de enfermar y contagiar a sus familiares. Muchos de ellos se aislaron en hoteles destinados a acoger sanitarios desfallecidos que dejaron de ver a sus seres queridos para escuchar aplausos colectivos que daban un atisbo de esperanza día tras día. Todo ello sabiendo que pacientes graves con otras patologías diferentes a la COVID-19 han sido relegados a un segundo plano ${ }^{14}$. El gran estrés emocional requiere especial atención a las necesidades de apoyo psicológico de todas las personas implicadas en la asistencia a estos pacientes. Cuidarse a sí mismo y animar a otros a autocuidarse mantiene la capacidad de seguir cuidando y contagiando salud. El compromiso profesional y la fortaleza no son incompatibles con sentir inquietud, miedo, tristeza, culpa o impotencia.

Reflexionar sobre el valor del trabajo realizado o compartir experiencias vividas puede ser de gran utilidad para fomentar la resiliencia y reducir el agotamiento ${ }^{15}$.

No queremos dejar de mencionar el extraordinario papel jugado por los trabajadores esenciales, hasta ahora tan poco valorados, que han sido claves en el mantenimiento de los servicios básicos para que todos pudiéramos sobrevivir.

\section{RELACIÓN MÉDICO PACIENTE EN LA NUEVA NORMALIDAD}

"Sienten la profunda necesidad de un calor que los una, sin embargo, no se abandonan a ella por la desconfianza que aleja a los unos de los otros" (Albert Camus, La Peste ${ }^{1}$.

La confianza es la clave de la relación médico-paciente y tiene un valor terapéutico. Pues bien, hasta esto se ha contaminado. El centro de atención fue curar descuidando el cuidar, parte esencial de nuestra profesión, con riesgo de caer en una deshumanización. Como bien expresa Pellegrino "la experiencia de ser curado va inexorablemente ligada al ser cuidado"16.

Respiramos desconfianza al acercarnos al otro, sin saber si es una persona contagiada. Se encubre el lenguaje corporal con batas, mascariIlas y guantes. El contacto visual es el elemento que permanece y debería ser intensificado de modo que seamos capaces de transmitir a través de nuestra mirada empática, el compromiso con el paciente y no perder la confianza, clave en dicha relación ${ }^{17}$. Busquemos estrategias que nos permitan mantener el trato humano ${ }^{18}$.

Además, en todas las películas citadas hay una escena en la que la mirada del profesional es el espejo de la frustración que siente, al verse limitado en su con-tacto con el paciente, 


\section{COVID-19, UNA PANDEMIA DE PELÍCULA: ANÁLISIS DE PROBLEMAS ÉTICOS \\ CELIA VICENTE MARTÍNEZ; CARMEN ÁLVAREZ GALÁN; ISOLINA RIAÑO-GALÁN}

precisando un esfuerzo extra para lograr empatizar y transmitir una mirada compasiva.

\section{MUERTE EN SOLEDAD}

Contagio (Contagion, 2011, Steven Soderbergh) refleja en medio del caos de la epidemia como la doctora Erin, durante su investigación, se contagia y acude a un polideportivo preparado para los infectados a falta de camas en los hospitales. Allí fallece sin poder despedirse de sus seres queridos y sin sanitarios que la atiendan, así como otros muchos enfermos.

La enfermedad con alta contagiosidad ha hecho que el aislamiento hospitalario de los casos sea exhaustivo, con absoluta exclusión del acompañamiento e incluso la asistencia espiritual al final de la vida. Las circunstancias no deberían de justificar que se haya generalizado la muerte en soledad de manera taxativa a todos los casos, ignorando si había alguna posibilidad de facilitar un mínimo acompañamiento.

De esta situación surgieron en redes sociales propuestas para enviar cartas con mensajes de apoyo a pacientes aislados. Sanitarios ofrecían su teléfono móvil a personas mayores para poder ver las caras de sus seres queridos, pues no se resignaban a creer que la soledad era la única norma correcta. La muerte en soledad no es concebida en la condición del ser humano, por parte del enfermo ni de los ojos que lo ven.

A la muerte en soledad le ha seguido, además, un duelo patológico. El duelo requiere tiempo para velar, rituales culturales y soporte social. Saber que un ser querido se encuentra congelado y tener que esperar el turno para recoger sus cenizas, como si de la cola de un supermercado se tratase, abre una herida en el alma que será difícil de cicatrizar.

\section{RESPONSABILIDAD INDIVIDUAL. AUTONOMÍA VS} BIEN COMÚN.

La responsabilidad se basa en la respuesta y el modo de responder acerca de lo que uno mismo ha hecho. Albert Camus, en su novela, $L a$ Peste $^{1}$, refleja muy bien esta dualidad del alma de Rambert, un periodista encerrado en la ciudad de Orán durante la epidemia de peste, que aúna todos sus esfuerzos en escapar de las fronteras y reunirse con su mujer en París. El Dr Rieux, cabecilla de los equipos sanitarios, es conocedor de la situación. Sin embargo, no juzga su decisión, la comprende, pues él también está separado de su esposa. Finalmente, Rambert, decide prestar su ayuda en beneficio de la sociedad de Orán.

Primero fue la ciudad de Wuhan y luego poco a poco las ciudades comenzaron a aislarse con medidas más o menos estrictas. En España 99 días de estado de alarma, 48 de ellos de confinamiento estricto, han coartado los derechos de movimiento de los ciudadanos, en favor del bien común. El derecho de autonomía se ha visto confrontado con la salud pública.

La pandemia ha puesto de relieve que nuestro derecho a la salud solamente puede garantizarse mediante nuestro deber para con la salud tanto a nivel individual como colectivo. Como señala la declaración de la UNESCO hay distintos niveles de responsabilidad ${ }^{19}$. Los gobiernos son responsables de garantizar la seguridad pública y la protección de la salud y concienciar a la ciudadanía de los métodos necesarios para lograrlo. La población tiene la responsabilidad de cumplir las normas que protegen a todos no solo como individuos sino de modo especial como sociedad. A modo ilustrativo el reconocimiento de la responsabilidad de cada uno conlleva hacer frente a las restricciones de la libertad, por ejemplo, el distanciamiento físico. Esto no significa aislamiento social de la persona ni pérdida de las relaciones sociales sino expresión del deber de mantener una distancia física adecuada en las actividades sociales para evitar la propagación de la enfermedad.

La autonomía es un principio ético prominente pero también relativo y condicionado. El límite de la autonomía personal viene marcado 
por no perjudicar al otro, a la comunidad. Somos interdependientes: el cuidado de uno mismo es el cuidado de los otros.

\section{INVESTIGACIÓN Y VACUNAS}

La carrera hacia la búsqueda de una vacuna dio el pistoletazo de salida el mismo día que se consideraba la COVID-19 como una enfermedad emergente potencialmente letal. Una vez controlada "la curva" es hora de centrar todos los esfuerzos en la investigación para encontrar la cura o la prevención de esta enfermedad. Muchos países se han embarcado en una competición política y económica con consecuencias no siempre favorables. La excepcionalidad de la emergencia actual ha llevado a considerar éticamente admisible la utilización de fármacos y vacunas en fase de investigación cuya eficacia y seguridad se desconocen.

Rememoramos uno de los más apasionantes enfrentamientos de la era moderna, la rivalidad Salk-Sabin; virus muertos inactivados vs virus vivos atenuados ${ }^{20}$. Después de la segunda guerra mundial, la esperanza de muchos países se ensombrecía cada verano cuando la poliomelitis se instalaba como un fantasma que atemorizaba a las sociedades. Una enfermedad con gran poder de contagio que afectaba sobre todo a niños y jóvenes, con un alto índice de mortalidad y discapacidades severas como secuelas de los supervivientes. El 12 de abril de 1955, se publicaba la noticia de que el Dr. Jonas Salk había descubierto la vacuna frente a la polio, a partir de un virus muerto, inactivado. Uno de sus colegas fue su gran oponente. El Dr. Sabin defendía la búsqueda de una vacuna de virus vivos atenuados, administrada por vía oral. Conllevó más años de investigación y fue lanzada en 1964. Sin embargo, las epidemias de polio que todos los años acontecían con las imágenes ominosas de niños con extremidades deformadas y esos pulmones de acero no permitían esperar más tiempo. A día de hoy, a pesar del enfrentamiento entre ambos, se considera que los esfuerzos de Albert Sabin y Jonas Salk en conjunto llevaron a la erradicación de la polio. Parafraseando a Philip Roth en su novela Némesis ${ }^{5}$, donde una epidemia de polio asola la sociedad de Newark en 1944, "en el deporte todo requiere determinación, las tres $D$ : determinación, dedicación y disciplina, y prácticamente lo habéis logrado".

Nosotros no, al menos aún. La cooperación en estos momentos es fundamental pero las fervientes ganas de conseguir la vacuna contra el SARS-CoV-2 no deben quemar etapas en la investigación ${ }^{21}$. Ser cautos en el avance y anteponer la seguridad a otros intereses menos morales.

COVID-19 ha puesto de manifiesto la importancia de la inversión en ciencia y en investigación, pero también que la bioética es parte esencial e imprescindible de la medicina. La urgencia en hallar una cura no debe impedir que se apliquen protocolos de investigación responsable, sujetos a criterios éticos.

\section{CONCLUSIONES PARA EL FUTURO}

Las consecuencias devastadoras e inmediatas que ha traído consigo la pandemia por COVID19 hacen difícil pensar en un futuro alejado de lo incierto y desalentador. Entre las asignaturas pendientes está la gestión emocional de la crisis y de la fatiga profesional, por el esfuerzo de aprender a tratar esta nueva enfermedad.

La reacción de tristeza forma parte de nosotros y como el resto de las emociones tiene su lugar, pero no dejemos que haga mella en nuestra historia, puesto que el fin último del ser humano es la felicidad. Aprovechemos la ocasión para reflexionar y construir colectivamente un mundo mejor y unas sociedades más preparadas para posibles catástrofes de esta índole ${ }^{22}$. Construyamos solidaridad y resiliencia, porque no hay nada que no se pueda soportar, siempre que se tenga un motivo por el que seguir adelante. Es nuestro deber como profesionales de la salud enfrentar 


\section{COVID-19, UNA PANDEMIA DE PELÍCULA: ANÁLISIS DE PROBLEMAS ÉTICOS \\ CELIA VICENTE MARTÍNEZ; CARMEN ÁLVAREZ GALÁN; ISOLINA RIAÑO-GALÁN}

la realidad, crear redes sólidas y brindar apoyo a los demás y a nosotros mismos ${ }^{23}$.

El cine nos muestra muchas veces un mundo distópico, una sociedad indeseable en sí misma tras una hecatombe global. Así en 12 monos (12 monkeys, 1995, Terry Gilliam) en el año 2035 los supervivientes de una pandemia se refugian en comunidades subterráneas, húmedas y frías. En Soy leyenda (/ am legend, 2007; Francis Lawrence) vemos una epidemia creada por el hombre, que transforma a los humanos en mutantes sedientos de sangre. Es hora de pensar si podemos actuar conjuntamente para evitar escribir un guion semejante al que ya nos han mostrado.

De aquí en adelante, las obras maestras de la literatura y el cine que pongan de manifiesto el impacto de una pandemia en un mundo global no serán categorizadas como ciencia ficción, sino como novelas y películas históricas, basadas en hechos reales.

"La principal tarea de los seres humanos y los pueblos es forjarse un carácter justo. Gracias a él resistiremos mejor las pandemias y las crisis porque lo haremos de forma solidaria" (Adela Cortina, 2020).

\section{REFERENCIAS}

1. Camus A. La peste. Paris: Editions Gallimard; 1996.

2. Gracia D. Las grandes epidemias históricas: peste, ergotismo, viruela, fiebre amarilla, cólera y sida. En: Gracia D. Lázaro J. Introducción a la medicina. Historia y teoría. Madrid: Editorial Hariadna; 2008; p 79-109.

3. CABEPA. Comisión Asesora de Bioética del Principado de Asturias. Reflexiones éticas para una situación de emergencia: COVID-19. Oviedo.[Internet]. 31 de marzo de 2020. [Consultado el 31 de marzo de 2020].

4. CBE. Comité de Bioética de España. Aspectos bioéticos de la priorización de recursos sanitarios en el contexto de la crisis del coronavirus. [Internet]. 25 de marzo de 2020. [Consultado el 31 de marzo de 2020].
5. Roth P. Némesis. New York: 1a edic. Houghton Mifflin; Harcourt, 2010.

6. The Hastings Center. Ethical Framework for Health Care Institutions Responding to Novel Coronavirus SARS-CoV-2 (COVID-19). Guidelines for Institutional Ethics Services Responding to COVID-19. [Internet]. 16 de marzo de 2020. [Consultado el 31 de marzo de 2020].

7. Hastings Center Report. Los fines de la Medicina. Cuadernos de la Fundació Víctor Grífols i Lucas, N.ㅇ 11. Barcelona: Fundació Víctor Grífols i Lucas; 2004.

8. Gracia D. Profesión médica, investigación y justicia sanitaria. Bogotá: Editorial El Búho: 2002.

9. Archard D, Caplan A, Connolly V. Is it wrong to prioritise younger patients with COVID-19? BMJ 2020;369:m1509

10. Fins JJ. Resuscitating patient rights during the pandemic: COVID-19 and the risk of resurgent paternalism. Camb Q Healthc Ethics. 2020, 1-7.

11. Sociedad Española de Medicina Geriátrica. Posicionamiento SEMEG respecto de las necesidades y derechos del paciente mayor en la situación actual de pandemia por COVID-19. SEMEG [Internet] 27 de marzo de 2020 [Consultado el 2 de septiembre de 2020]

12. Kübler-Ross E. On Death and Dying. New York: Macmillan; 1969.

13. Seoane JA. Bioética, lenguaje y COVID 19. Bioética Complutense. 2020; 39: 52-6.

14. Rosenbaum L. The Untold Toll - The Pandemic's Effects on Patients without Covid-19. N Engl J Med. 2020; 382(24):2368-71.

15. Rosenberg AR. Cultivating Deliberate Resilience During the Coronavirus Disease 2019 Pandemic. JAMA Pediatr. 2020;174(9):817-8.

16. Pellegrino E.D. Esencia y sentido de la medicina. En: Filosofía de la Medicina. Francesc Torralba i Roselló (ed). Institut Borja de bioética. Madrid. Fundación Mapfre Medicina; 2001

17. Vallelonga F, Elia F. Doctor-patient relationship at the time of COVID?19: travel notes. Intensive Care Med. 2020; 46:1802.

Rev. Med. Cine. 2020; 16 (e), 183-193 Ediciones Universidad de Salamanca / @®@® J. Med. Mov., 2020; 16 (e), 183-193 


\section{COVID-19, UNA PANDEMIA DE PELÍCULA: ANÁLISIS DE PROBLEMAS ÉTICOS \\ CELIA VICENTE MARTÍNEZ; CARMEN ÁLVAREZ GALÁN; ISOLINA RIAÑO-GALÁN}

18. Sagara R, Chawl N, Sen M. Preserving the "human touch" in times of COVID-19. Asian J Psychiatr. 2020: 54: 102224.

19. UNESCO. Declaración sobre el COVID-19: Consideraciones éticas desde una perspectiva global. Paris, 6 de abril de 2020 (traducción al español del Centro Nacional de Documentación en Bioética, La Rioja. España.

20. Bauso M. Salk vs Sabin: las epidemias de polio, la vacuna y el enfrentamiento feroz entre los científicos. Infobae [Internet] 14 de abril de 2020.
21. London AJ, Kimmelman J. Against pandemic research exceptionalism. Science 2020; 368 (6490), 476-7.

22. Rodríguez Diaz JA. La COVID-19: la gran oportunidad para pensar y crear sociedades futuras mejores. RES. 2020; 29(3): 693-702.

23. Esquerda M, Rubio $\mathrm{O}$, Amblàs J, Pifarré J. La medicina cambia rápidamente. En un instante, la medicina tal como la conoces se acaba. Bioetica Debat. 2020; 26(87): 11-5.

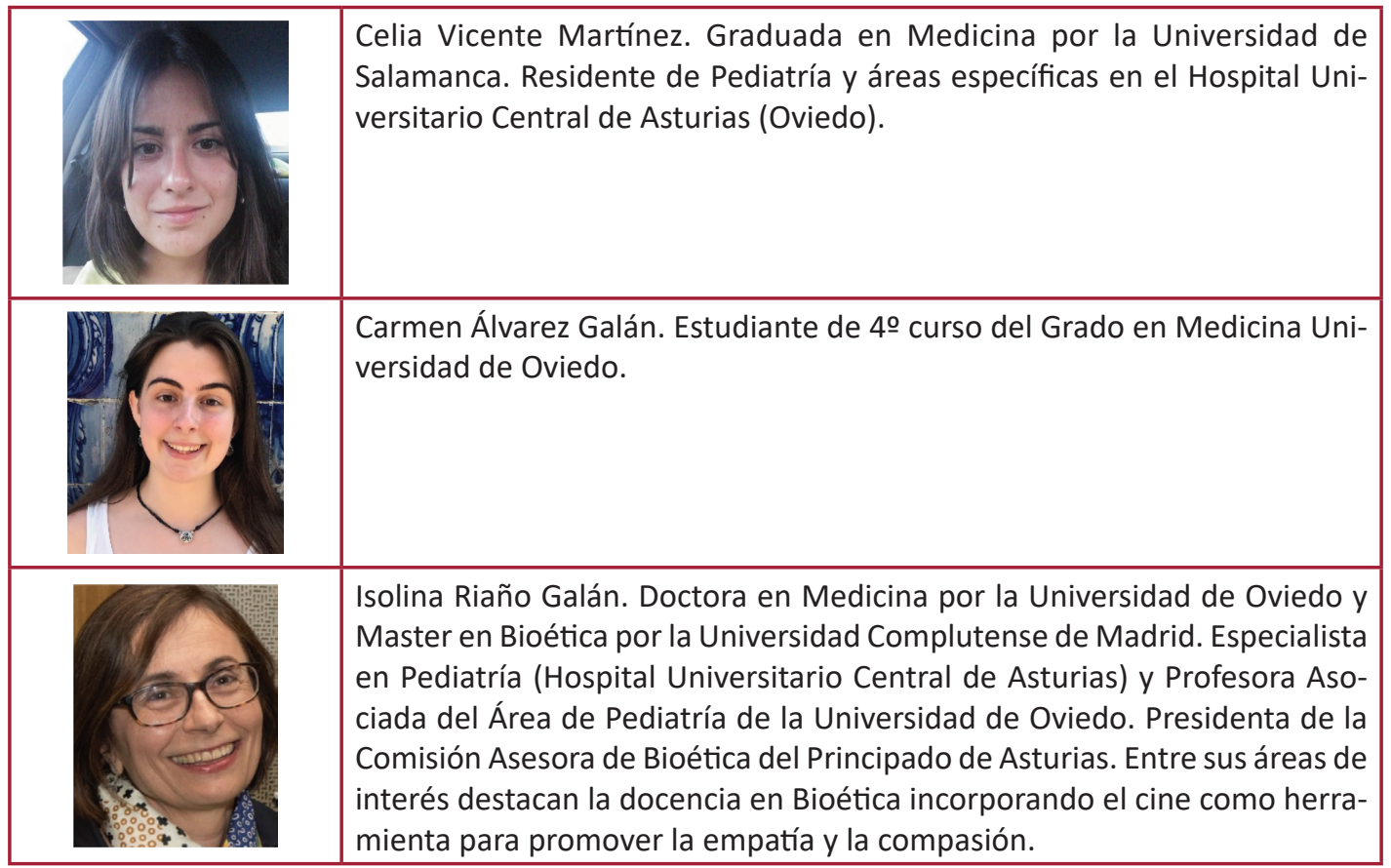

